\title{
AUTOMATIC LIDAR CALIBRATION AND PROCESSING PROGRAM FOR MULTIWAVELENGTH RAMAN POLARIZATION LIDAR
}

\author{
Zhenping Yin ${ }^{1,2,3, *}$, Holger Baars ${ }^{1}$, Patric Seifert ${ }^{1}$, Ronny Engelmann ${ }^{1}$ \\ ${ }^{1}$ Leibniz Institute for Tropospheric Research, Permoserstraße 15, 04318 Leipzig, Germany \\ ${ }^{2}$ School of Electronic Information, Wuhan University, Wuhan, China \\ ${ }^{3}$ Key Laboratory of Geospace Environment and Geodesy, Ministry of Education, Wuhan, China \\ *Email: zhenping@tropos.de
}

\begin{abstract}
A new version of automatic lidar calibration and processing program was developed to process the data from multiwavelength Raman polarization lidar. The absolute lidar calibration and water vapor calibration algorithms were applied. The program can provide plentiful products, like aerosol backscatter and extinction coefficients, lidar ratio, Ångström exponent, volume and particle depolarization ratios, water vapor mixing ratio and aerosol target classification. Good agreement was found in the comparison with manual quality-assured profiles or radiosonde measurement. Lidar calibration based on the aerosol optical properties retrieved with Raman method, Klett method and AOD-Constrained method were implemented. Good consistency was found.
\end{abstract}

\section{INTRODUCTION}

Aerosol can influence the Earth radiation budget by absorption and scattering solar radiation, and modulate cloud formation and cloud microphysical properties. Therefore, obtaining the vertically resolved aerosol optical and microphysical properties is very important for climate modeling. Lidar, as a very efficient detection tool for aerosol measurement, can provide highly resolved vertical and temporal information. In order to observe the aerosol distribution in a large scale, several ground-based lidar networks were also established, e.g. EARLINET [1], the ceilometer network of the German Meteorological Service (DWD, [2]), MPLNET [3] and multiwavelength Raman polarization lidar network PollyNET [4]. However, more systems bring more data, which can easily exceed our limit of manual analysis capacity. Although there are some automatic algorithms and programs for lidar data processing, most of them are only suitable for single wavelength or elastic lidar systems ([5], [6]). In order to realize automatic analysis for multiwavelength Raman polarization lidar measurements, the first version of the automatic lidar processing program was developed to obtain aerosol backscatter and extinction coefficients, lidar ratio and volume/particle depolarization ratio [4]. As the emerging of water vapor calibration and aerosol target classification algorithms, we designed a more powerful version to include new products, like water vapor mixing ratio, relative humidity, lidar calibration constants and aerosol target classifications.

\section{POLLYXT}

Polly ${ }^{\mathrm{XT}}$ is a multiwavelength Raman polarization lidar system [7]. It has 12 channels with $355 \mathrm{~nm}$, $387 \mathrm{~nm}, 532 \mathrm{~nm}$ and $607 \mathrm{~nm}$ at near- and farrange channels, $355 \mathrm{~nm}$ and $532 \mathrm{~nm}$ at cross channels, $407 \mathrm{~nm}$ and $1064 \mathrm{~nm}$ at far-range channels. The incomplete overlap zone for farand near-range channels have been suppressed to 500 and $120 \mathrm{~m}$. The system is operated $24 / 7$ with a raw resolution of $7.5 \mathrm{~m}$ and $30 \mathrm{~s}$ and only water vapor channel needs to be turned off at daytime.

\section{METHODOLOGY}

The flowchart of the new processing program is presented in Fig. 1. The entire structure is very straightforward and consists of well-defined modules and algorithms ([8], [9], [10], [11]). In the first step, the raw signal is pre-processed with deadtime correction, background correction and first bin adjustment. Then, the 355 and $532 \mathrm{~nm}$ cross channels are calibrated with $\pm 45^{\circ}$ calibration method [8], see Fig. 2c. This calibration process is implemented three times a day to ensure reliable results. After that, the profiles with cloud contamination are screened out based on the derivative of the range corrected signal at both near- and far-range channels, see 


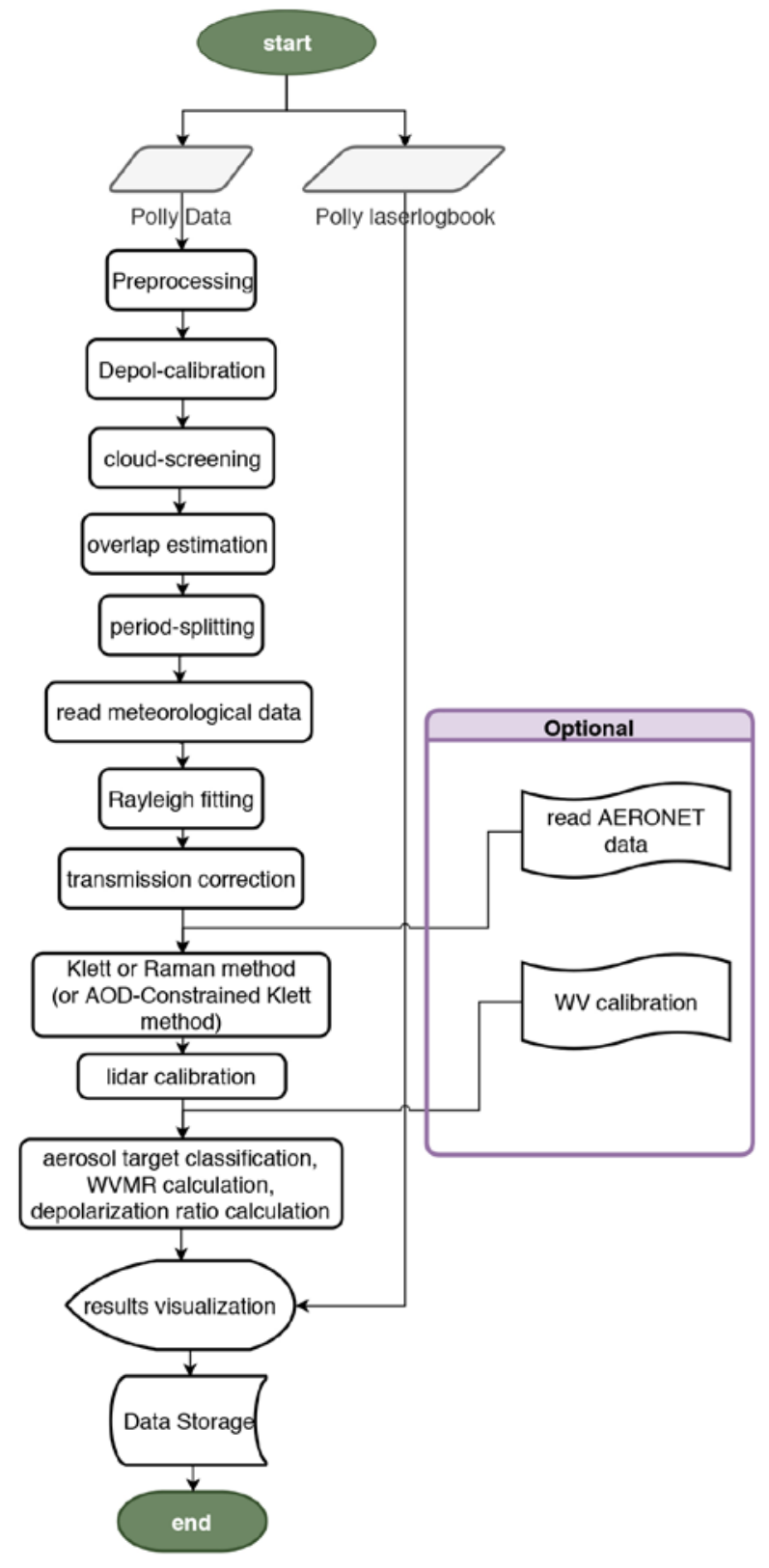

Figure 1. Flowchart of the PollyNET processing chain. (Optional parts mean the modules are dependent on the available AERONET sites nearby).

Fig. 2d. The remained cloud-free profiles are divided into several 1-hour continuous subgroups and integrated for further analysis. Then the Rayleigh fitting algorithm [11] is applied to search for the reference height (nearly aerosol-free region). After that, the Klett method [12], Raman method [13] and AOD-Constrained method [14] are implemented according to the SNR of Raman signal and the availability of sunphotometer measurements. The lidar ratios of $55 \mathrm{sr}, 55 \mathrm{sr}$ and
$55 \mathrm{sr}$ at 355,532 and $1064 \mathrm{~nm}$ are used in Klett method. The elastic far-range channels are absolutely calibrated based on the retrieved aerosol profiles. The calibration range is determined with the smallest variability of the calibration results within a sliding window. After the lidar calibration, the aerosol classification algorithm is implemented to differentiate the aerosol types according to the size and shape of the particles [10]. This is the entire structure of the calibration and processing program. The source code is based on MATLAB and can be freely accessed via GitHub [15].

\section{RESULTS}

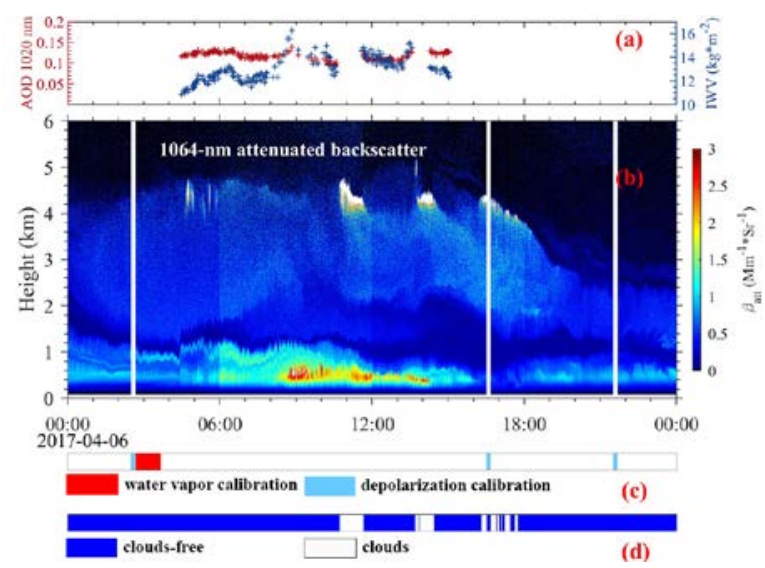

Figure 2. Dust case on 6 April 2017 at Limassol, Cyprus. (a) Level 1.5 data from AERONET (red: $1020 \mathrm{~nm}$ AOD, blue: IWV), (b) height-time plot of 1064 nm attenuated backscatter with Polly ${ }^{\mathrm{XT}}$ and (c) calibration and cloud status for each profile.

\subsection{Vertical profiles}

In Fig. 3, we presented the aerosol vertical profiles from the automatic processing program and manual standard EARLINET analysis during the period of 00:00-00:59 UTC on 6 April 2017. The detailed aerosol evolution can be checked in Fig. 2b. For the comparison in Fig. 3, we can find very good agreement for the backscatter and extinction coefficients and volume/particle depolarization ratio.

\subsection{Water vapor calibration results}

The water vapor channel can be calibrated with the integrated water vapor (IWV) either from 


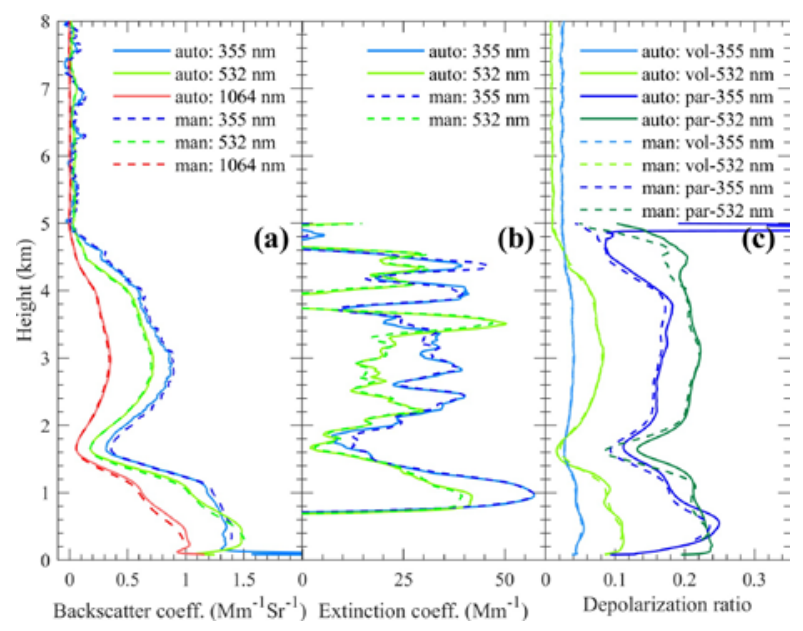

Figure 3. Comparison of manually (man) and automatically (auto) derived aerosol optical properties for 6 April 2017 in Limassol, Cyprus, averaged from 00:00 to 00:59 UTC. (a) aerosol backscatter coefficient at $355 \mathrm{~nm}, 532 \mathrm{~nm}$ and 1064 $\mathrm{nm}$, (b) aerosol extinction coefficient at $355 \mathrm{~nm}$ and $532 \mathrm{~nm}$ and (c) volume and particle depolarization ratio at $355 \mathrm{~nm}$ and $532 \mathrm{~nm}$.

collocated sunphotometer [9] or from microwave radiometer measurements [16]. For the case on 06 April 2017 at Limassol, Cyprus, we used the sunphotometer measurement at 04:30 UTC for the calibration and the water vapor calibration constant was $6.50 \mathrm{~g} \mathrm{~kg}^{-1}$. This constant was used to calculate the water vapor mixing ratio with lidar at 02:41-03:40 UTC to compare with radiosonde measurement (see Fig. 4). We can find very good agreement between them.

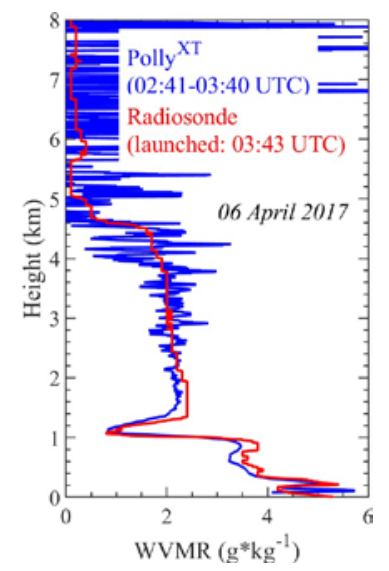

Figure 4. Comparison of water vapor mixing ratio profile with Polly ${ }^{\mathrm{XT}}$ and radiosonde.

\subsection{Lidar calibration results}
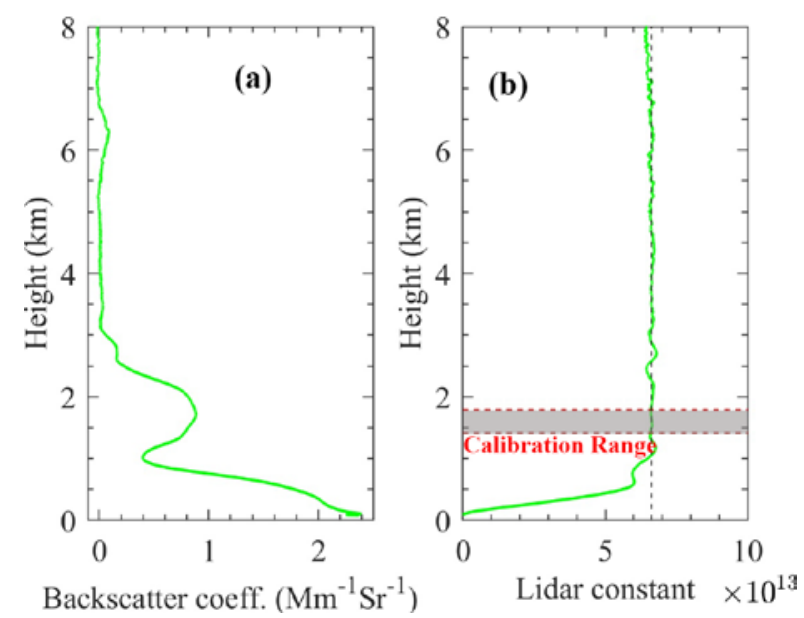

Backscatter coeff. $\left(\mathrm{Mm}^{-1} \mathrm{Sr}^{-1}\right)$

Figure 5. Lidar calibration results on 06 April 2017, at Limassol, Cyprus. (a) Aerosol backscatter coefficient at $532 \mathbf{~ n m}$ with Raman method, averaged from 22:41 to 23:59 UTC, (b) lidar calibration constant profile.

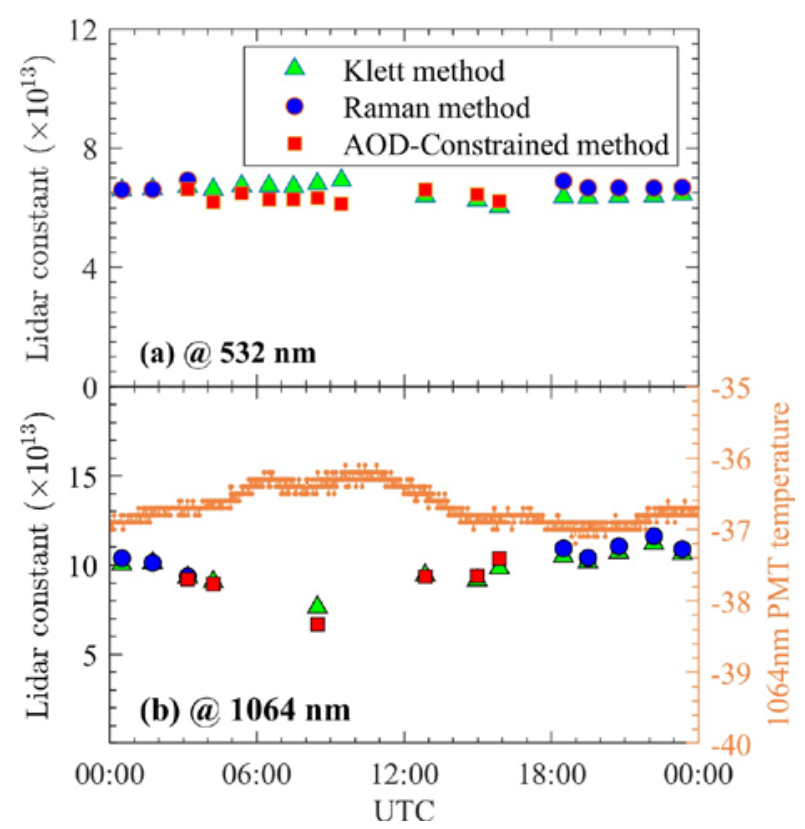

Figure 6. Time series of lidar constants at $532 \mathrm{~nm}$ (a) and 1064 nm (b) with Klett method, Raman method and AOD-Constrained method on 06 April 2017 at Limassol, Cyprus.

According to single-scattering elastic lidar equation [12], the lidar system can be absolutely calibrated with accurately obtained aerosol backscatter and extinction profiles [17]. Normally, the extinction coefficient profile with Raman method is very noisy and can hardly be used to calibrate the lidar system in an automatic way. Instead, we used the backscatter coefficient multiplied with a fixed lidar ratio of $55 \mathrm{sr}$. With 
the constrain of AOD to be less than 0.3, this simplification introduces an error less than $10 \%$ for the lidar calibration under the conditions of clean and polluted continental aerosol, dust and smoke [10]. At the height with incomplete overlap, the backscatter coefficient with Klett method or AOD-Constrained method is considered as heightindependent. This leads to an error less than $10 \%$ for Polly ${ }^{\mathrm{XT}}$ lidar and can be further reduced with overlap correction. In Fig. 5, we showed the lidar calibration results at $532 \mathrm{~nm}$ on 06 April 2017 22:41-23:59 at Limassol, Cyprus. The backscatter coefficient profile in Fig. 5a was retrieved with Raman method. The lidar constant profile was displayed in Fig. 5b and the calibration program calculated the lidar constant within the most stable region, which located between 1.4 and $1.8 \mathrm{~km}$ in this case. In Fig. 6, the whole day lidar calibration results on 06 April 2017 were presented. In Fig. $6 a$, we can see the calibration results with different retrieving methods are very stable and in good agreement. In Fig. 6b, we can see some variations at daytime. And the variations could be explained by the change of $1064 \mathrm{~nm}$ PMT temperature at daytime.

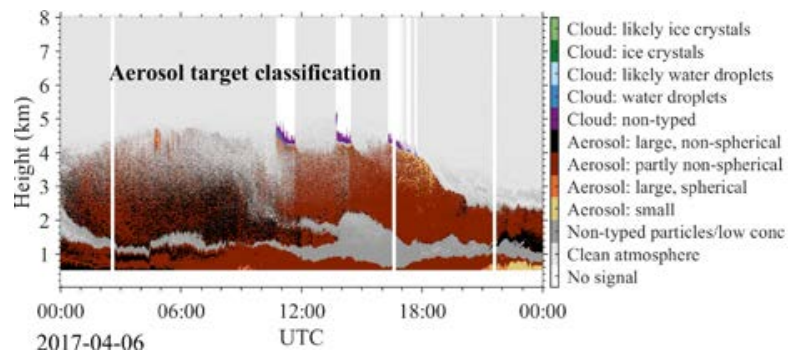

Figure 7. Aerosol target classifications on 6 April 2017 for Limassol, Cyprus.

\subsection{Aerosol target classification}

With the lidar calibration constants at $532 \mathrm{~nm}$ and $1064 \mathrm{~nm}$, the aerosol target classification algorithm can be implemented to obtain the aerosol morphology information [10].

In Fig. 7, the aerosol classification result on 6 April 2017 at Limassol, Cyprus was displayed. Partly non spherical and large non-spherical aerosol were dominant in the whole day. These categories normally stand for mixed dust or dust particles. This finding was corroborated by the backward trajectories, which showed that partly of the trajectories can be traced to European continent and partly can be traced to Saharan desert (not shown here).

\section{ACKNOWLEDGEMENTS}

This work was funded by the European Union's Horizon 2020 research and innovation programme under grant agreement nos. 654109 (ACTRIS-2) and 763643 (EXCELSIOR). The authors appreciated the support from Cyprus University of Technology and Remote Sensing and GeoEnvironment Lab (ERATOSTHENES Research Centre) during CyCARE. Zhenping Yin thanks the support from the Chinese Scholarship Council (CSC) to conduct this research under the CSC no. 201706270117.

\section{REFERENCES}

[1] G. Pappalardo, et al. Atmospheric Measurement Techniques 8: 2389-2409 (2014)

[2] H. Flentje, et al. Atmospheric Measurement Techniques Discussions 3: 3643-3673 (2010)

[3] E.J. Welton, et al. Proc. SPIE, 4153, 151-158 (2001)

[4] H. Baars, et al. Atmospheric Measurement Techniques 16.8: 5111-5137 (2016)

[5] Y. Morille, et al. Journal of Atmospheric and Oceanic Technology 24.5: 761-775 (2007)

[6] A. Omar, et al. Journal of Atmospheric and Oceanic Technology 26.10: 1994-2014 (2009)

[7] R. Engelmann, et al. Atmospheric Measurement Techniques 9.4: 1767-1784 (2016)

[8] V. Freudenthaler, et al. Tellus B 61.1: 165-179 (2009)

[9] G. Dai, et al. Atmospheric Measurement Techniques 11.5: 2735-2748 (2018)

[10] H. Baars, et al. Atmospheric Measurement Techniques 10.9: 3175 (2017)

[11] V. Freudenthaler, Lidar Rayleigh-fit criteria, in: EARLINET-ASOS 7th Workshop, available at: https://epub.ub.uni-muenchen.de/12970/ (2009)

[12] J.D. Klett, Applied Optics 20.2: 211-220 (1981)

[13] A. Ansmann, et al. Applied Optics 31.33: 71137131 (1992)

[14] B. Heese, et al. Atmospheric Measurement Techniques 3.6: 1763-1770 (2010)

[15]

https://github.com/PollyNET/Pollynet_Processing_Cha in

[16] A. Foth, et al. Atmospheric Chemistry and Physics 15.14: 7753-7763 (2015)

[17] Y. Wu, et al. Proc. Of SPIE Vol.7479 (2009) 